\title{
ON THE HIERARCHICAL LEVELS OF DESIGN KNOWLEDGE
}

\author{
S. Kolarić ${ }^{1, \bigotimes}$, J. Beck ${ }^{2}$ and E. Stolterman ${ }^{3}$ \\ ${ }^{1}$ Georgia Institute of Technology, United States of America, ${ }^{2}$ Milwaukee School of Engineering, United States of \\ America, ${ }^{3}$ Indiana University, United States of America \\ $凶$ skolaric@gatech.edu
}

\section{Abstract}

Hierarchies of knowledge represent a popular formalism for conceptualizing beliefs, justifications, and truth statements. To capitalize on the opportunity for formulating effective maps of design knowledge, this article introduces the hierarchical context-design development-high-level (CDH) model that stratifies different bodies of design-specific knowledge into ranked levels. We compare it with existing hierarchical models of knowledge, and describe its unique uses and benefits for both design research and design practice.

Keywords: design theory, design knowledge, design models, epistemology of design

\section{Introduction}

Design inquiry is concerned with the study of difficult, "wicked" design problems. Notably, design problems require human judgment, cannot be readily partitioned into independent subproblems, lack formal methods or clear criteria to evaluate, and frequently involve disagreements among domain experts (Lynch et al., 2009). One of the principal aims of design inquiry is "the study of the principles, practices, and procedures of design" (Cross, 2001).

Within design inquiry, one important stream of research belongs to design theory, or a formal set of ideas about various aspects of the phenomenon of design. Le Masson et al. (2013) state that four main issues faced by the field of design theory include lack of unity of the field, constantly changing paradigms of design, the existence of many fragmented design communities and schools of thought, and the inability to reference a unified theoretical model when conducting empirical design studies. Hatchuel et al. (2017) recently presented a design theory framework, which suggests and clarifies an ontology of design, based on the concepts of generativity, independences of knowledge structures, and social spaces for design.

In this article, we will likewise examine design from this knowledge-centric or epistemological theoretical perspective on design, which has recently been gaining importance. Design is inherently linked to knowledge structures (Hatchuel et al., 2017). The study of design includes "reflection on the nature and extent of design knowledge and its application to design problems" (Cross, 1984).

Going beyond design research, since designers nowadays exercise their profession in knowledgebased-economies, they must correspondingly master a range of knowledge-related skills and competencies (Gardien et al., 2014). Such skills may include knowledge transfer (communication, instruction, and coaching), knowledge encoding (e.g., modeling, sketching, writing, and digital content creation), knowledge acquisition (i.e. learning and research), knowledge synthesis (reasoning and 
problem framing), and knowledge reuse. Yet, viewing design through a lens of knowledge raises some interesting questions, such as the following:

- What are some of the typical bodies of design knowledge, and how do they relate to each other?

- How are bodies of design knowledge refined, developed, and iterated on?

- How can bodies of design knowledge be organized into an overarching structure or cognitive map of design knowledge?

We believe that illuminating these issues can help with understanding the epistemological and methodological foundations of design and design-based research, as well as help inform design practice. To develop the overall argument, in Section 2 we first give an account of how design knowledge was acquired, synthesized, and refined during an interaction design project. Based on these considerations we present the context-design development-high level (CDH) hierarchy of design knowledge in Section 3. We conclude by discussing various aspects of the model in Section 4.

\section{The genesis of design knowledge in CAMBRIA}

The inspiration for introducing the formal $\mathrm{CDH}$ hierarchy of design knowledge derives from the CAMBRIA interaction design (IxD) research project (Kolarić et al., 2014, 2017), which involved the conceptualization and development of innovative parametric computer-aided design (pCAD) software tools. The main idea behind these tools was to allow to quickly and easily view, edit, compare, and manage multiple geometric design alternatives in parallel (Woodbury et al., 2013). We note that while the $\mathrm{CDH}$ model was motivated by this particular instance of IxD research, the scope of CDH is general, and it can be applied to any type of design.

The overall research process of CAMBRIA was divided into four major stages: pre-design, conceptual design, prototyping, and consolidation. Although the project followed this linear sequence, we note that CAMBRIA researchers alternated pragmatically and contingently between stages, similarly to the account given by Sedlmair et al. (2012).

We note that each stage of the CAMBRIA project resulted in the identification, creation, validation, and refinement of several bodies of design knowledge (BDKs). The researchers kept close track of the said bodies of design (in this case, IxD) knowledge at each stage (Table 1).

Table 1. Stages of IXD research in the CAMBRIA project: aims, BDKs, and activities

\begin{tabular}{|l|l|l|l|l|}
\hline $\begin{array}{l}\text { Stage } \\
\text { No. }\end{array}$ & Stage name & Principal aim & BDKs initiated & Typical activities \\
\hline 1 & Pre-design & $\begin{array}{l}\text { To broadly } \\
\text { explore the } \\
\text { IxD research } \\
\text { problem. }\end{array}$ & $\begin{array}{l}\text { - Annotated bibliography } \\
\text { - Initial set of requirements } \\
\text { - Interaction sketches } \\
\text { - GUI sketches } \\
\text { - GUI mockups }\end{array}$ & $\begin{array}{l}\text { Research of past work } \\
\text { Ethnography (users) } \\
\text { Ideation } \\
\text { Sketching } \\
\text { Wireframing }\end{array}$ \\
\hline 2 & $\begin{array}{l}\text { Conceptual } \\
\text { design }\end{array}$ & $\begin{array}{l}\text { To develop the } \\
\text { conceptual } \\
\text { model. }\end{array}$ & $\begin{array}{l}\text { - Interaction metaphors } \\
\text { - Set of concepts } \\
\text { - Relationships among concepts }\end{array}$ & $\begin{array}{l}\text { Research of past work } \\
\text { Ideation } \\
\text { Updating of BDKs }\end{array}$ \\
\hline 3 & Prototyping & $\begin{array}{l}\text { To develop } \\
\text { higher-fidelity } \\
\text { prototypes. }\end{array}$ & $\begin{array}{l}\text { - A series of increasingly more } \\
\text { sophisticated interactive prototypes } \\
\text { - Evaluation results }\end{array}$ & $\begin{array}{l}\text { Designing } \\
\text { Evaluating } \\
\text { Building } \\
\text { Updating of BDKs }\end{array}$ \\
\hline 5 & Consolidation & $\begin{array}{l}\text { Development } \\
\text { of high-level } \\
\text { BDKs. }\end{array}$ & $\begin{array}{l}\text { - A taxonomy of interaction primitives } \\
- \text { A set of guidelines } \\
\text { - A set of design principles }\end{array}$ & $\begin{array}{l}\text { Reflection } \\
\text { Introspection } \\
\text { Writing }\end{array}$ \\
\hline
\end{tabular}

While the available space precluded an in-depth account of the observed life cycles of BDKs (for details please refer to Kolarić (2016)), we observed the following two main phenomena: 
a) Progressive elaboration of BDKs. We noticed that BDKs undergo the process of progressive elaboration. We believe that the following elaboration activities are related to BDKs: detection (discovery), initiation, development, refinement, evaluation, and validation. This is corroborated by, for example Weick (1989), who writes that theories (including design theories) become gradually clearer as if "bringing binoculars into sharper focus". Le Masson and Weil (2013), while describing the method of ratios by F. Redtenbacher (1809-1863), similarly write that "step by step, the unknown object becomes more and more defined".

b) Relationships among BDKs. Any BDK affects other BDKs, with varying strength or intensity, thus resulting in a network of relationships among BDKs. For example, Rzevski (1981) writes that "every design solution (that is, every artefact produced as a result of design) will inevitably change equilibrium relationships within its environment and thus create unforeseen problems". We identified the following types of relationships among BDKs: influences, givesrise-to, and validates.

Upon reflecting on the outcomes of the project, the CAMBRIA researchers categorized BDKs into three main categories, thus giving rise to the following formal hierarchical model of design knowledge.

\section{The CDH hierarchical model of design knowledge}

Based on the considerations in the previous section, we introduce a hierarchical model of design knowledge (Figure 1), which organizes the aforementioned BDKs into an overarching structure. We hereby name it $C D H$ hierarchy, based on the initial letters of its three main levels: context, design state, and high-level design knowledge.

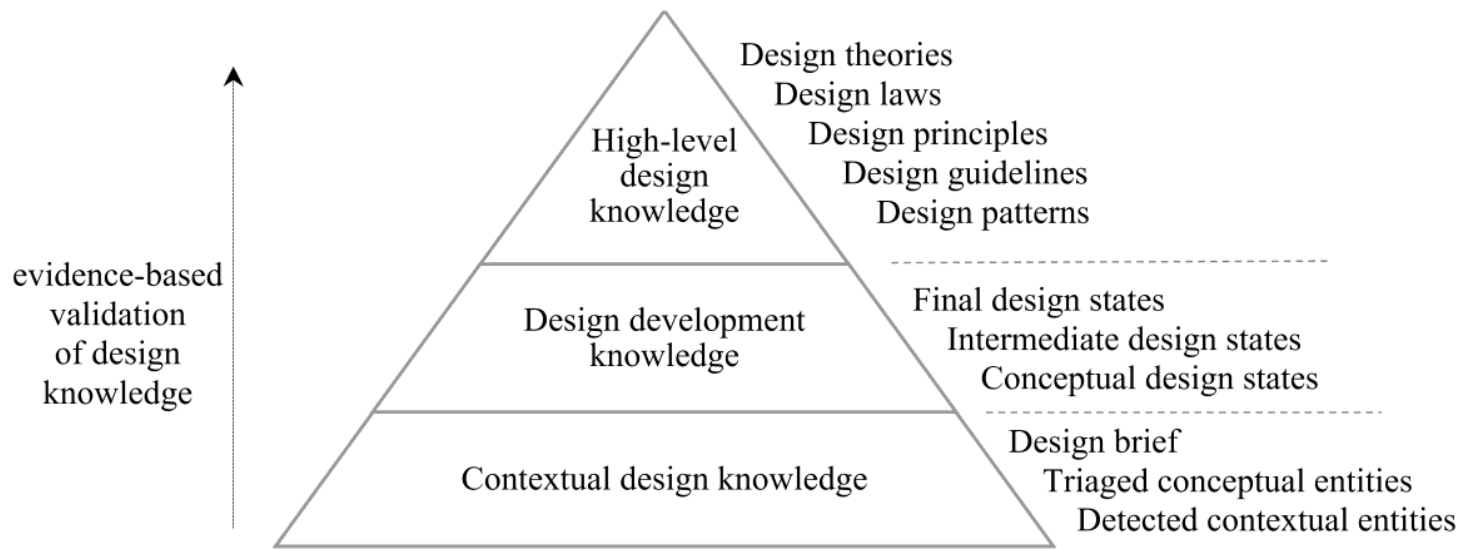

Figure 1. The $\mathrm{CDH}$ (context - development - high level) hierarchy of design knowledge

In the $\mathrm{CDH}$ model, each level emerges from the preceding (lower) one, transformed by a number of cognitive processes common to design practice and design research. The figure also illustrates the upward directions of information-imparting, generalizing, and validation of design knowledge.

\subsection{Base level: contextual design knowledge}

The base level of the model contains contextual design knowledge. The term design context (or simply context) denotes the subset of the general environment that is related to the design problem at hand. Following Parent (1992), Daase and Kessler (2007) as well as Le Masson and Weil (2013), we propose that a designer's contextual design knowledge progresses through the following sub-layers:

- Undetected contextual entities. This sub-layer contains entities the designer is not aware of yet, and are therefore still outside the designer's CDH hierarchy (unknown unknowns).

- Detected contextual entities. This sub-layer contains entities that the designer has become aware of and which might undergo a process of elaboration. In other words, these are known unknowns, which may gradually transition into known knowns. 
- Triaged contextual entities. This sub-layer contains relevant detected contextual entities or entities that have the potential to directly influence the design problem at hand.

- Design brief. The design brief contains a statement of personal or organizational needs, desires, constraints, and the overall design problem.

This sub-structure, in turn, suggests the importance of the activities of observe, analyze and understand. In the literature, these correspond to, for example, the define and discover phases of design (Zimmerman et al., 2004), the discover phase in the "double-diamond" model of design (British Design Council, 2007), the learn, winnow, cast, and discover activities mentioned by Sedlmair et al. (2012), and the clarify the task activity proposed by Pahl and Beitz (2007). Some common methods for discovering and acquiring contextual design knowledge include end user interviews, ethnographic studies, focus groups, and various methods for eliciting design requirements.

\subsection{Middle level: design development knowledge}

The middle level contains knowledge about design states, which from a knowledge-centric viewpoint of design can be understood as embodied knowledge (Cross, 2001; Stolterman and Wiberg, 2010), the thinking embodied in an artifact (Frayling, 1993), or objects that contain knowledge of what the product should be (Cross, 1999). As shown in Figure 1, we classify design development knowledge into the following three sub-levels commonly encountered in the literature and practice (see e.g. Pahl and Beitz, 2007):

- Conceptual design states that are generated during the ideation stage.

- Intermediate design states, which are of preliminary nature.

- Final design states or those that can be used for realizing the final product.

In addition to these three stages, Taura and Nagai (2013) present a theory for very early stages of design, or for design activities that immediately precede (or coincide with the very beginning) of the conceptual design stage. In their approach, generated concepts can either be of the first order (this generation is problem-driven) or of the high order (driven by the designer's "inner sense"). These concepts are then fed into the next stage, namely conceptual design.

The design development knowledge level is characterized by the intensive employment of abductive reasoning (Kolko, 2010; Dorst, 2011). This should be qualified by the fact that abduction adopts a hypothesis rather than invents one; the latter is more desirable in order to achieve generativity, or the "capacity to generate new propositions that are made of known building blocks but are still different from all previously known combinations of these ... blocks" (Hatchuel et al., 2017).

Regarding the activities for developing design knowledge at this level, an agreement exists, for example, among the construct and refine phases of design (Zimmerman et al., 2004), the define and develop phases in the double-diamond design process model (British Design Council, 2007), and the design, implement and deploy activities in visualization (Sedlmair et al., 2012). In general, the creation of design states lies in the domain of design methods.

\subsection{High-level design knowledge}

Based on the experience accumulated by developing many design states, possibly over multiple design projects within the same design sub-discipline, a designer or design researcher may optionally proceed with the generation of high-level design knowledge. We place these BDKs at the pinnacle of the CDH model, thus indicating their highly derivative and generalized nature, as well as the that they are informed by the lower levels of the hierarchy. Some of the BDKs in this layer include the following:

- Design patterns. A design pattern is a general or templatized design solution that can be used to solve instances of recurring design problems. Examples of design patterns can be found in architectural and urban design (Alexander et al., 1977), product design (Razzaghi et al., 2009), and object-oriented software design (Vlissides et al., 1995). We place design patterns as the first sub-level in this level, since they can be inferred and generalized directly from the immediately preceding detailed design solutions sub-layer in the design development level. 
- Design guidelines. Design guidelines are relatively low-level recommendations or suggestions that help designers frame and conceptualize any given design problem as well as heuristically evaluate design solutions for a design problem. Illustrative examples include design guidelines in architectural and urban design (Marcus et al., 1986), interaction design (Shneiderman and Plaisant, 2010), product design (Green and Jordan, 1999), and structural engineering design (Schnerch et al., 2007).

- Design principles. Compared to design guidelines, design principles are of a more general, universal, and abstract nature since they tend to be "more fundamental, widely applicable, and enduring" (Shneiderman and Plaisant, 2010, p. 62). Additional examples of design principles can be found in product design, for example (Rams, 2019), and software design (Vlissides et al., 1995).

- Design laws and theories. In this article, we consider design laws to be the equivalent of laws as understood in engineering and the sciences, or as small theories that underwent repeated testing and confirmation. For instance, Fitts' law (1954) can inform the design of interactive, pointer-based devices. A design theory, on the other hand, is a coherent and comprehensive body of knowledge that prescribes, predicts, or explains observations or facts related to some aspect of design (or class of design problems) at hand. Examples include theories associated with architectural and urban design (Mahy et al., 1987) and interaction design (Carroll, 2003), and those at the intersection of architecture and psychology (Gibson, 1976).

In addition to the bodies of high-level design knowledge listed above (as shown in Figure 1), other BDKs might presumably be added to the topmost tier of the $\mathrm{CDH}$ model in the future. For example, relatively low-level "design recommendations" (Mariage et al., 2005) may be considered as a sub-type of design guidelines. Likewise, "design concepts" (Stolterman and Wiber, 2010; Höök and Löwgren, 2012) may be considered as a BDK midway between design patterns and design guidelines.

Regarding activities used to generate knowledge at this level, there is a strong agreement between, for example, the high-level design knowledge and the understanding and wisdom layers in Ackoff's model (see Section 4.2); with such knowledge being externalized through the write activity (Sedlmair et al., 2012), as well as with the reflect phase of design (Zimmerman et al., 2004). In general, highlevel DBKs are created through the methods of introspection and reflection (Sedlmair et al., 2012).

\section{Discussion}

With regard to the design theory criteria noted by Le Masson et al. (2013), due to its beneficial generality the $\mathrm{CDH}$ model has the potential to bring together individuals from different design professions and different design research communities and societies, and provide an unifying framework (among many other possible unifying frameworks) that may integrate different design theories proposed in the past. It may also function as a "fixed" stable point in design research, in the sense that it remains invariant with regard to the design paradigm or design research methodology that is considered or used.

Next, we discuss how the CDH hierarchy relates to previously reported design theories. Then, we compare the $\mathrm{CDH}$ hierarchy to other reported hierarchical models of knowledge both in the nondesign and design fields of inquiry. Finally, we discuss some of its additional benefits.

\subsection{Relation to existing design theories}

Due to its general meta-theoretical nature, wide scope and hetero-disciplinarity, the CDH model can integrate many different design theories that have been proposed in the past. For instance, Hatchuel and Weil $(2003,2009)$ introduced the "C-K" theory that focuses on design states, and therefore can be accommodated within the middle layer in the $\mathrm{CDH}$ model. The augmentation of the $\mathrm{C}-\mathrm{K}$ theory with the third space (E) by Kazakçi and Tsoukias (2005) accounts for the contextual design knowledge level; however, this expanded theory does not account for higher-level BDKs, such as design patterns and design theories.

The same observation applies to the FSB (function-behavior-structure) theory by Gero and his collaborators $(1990,2004)$; it covers only the base and middle layers of the CDH model. The 
mathematical framework by Braha and Reich (2003), which is based on the evolution of function and structure spaces as well as their closures, is likewise subsumed by the CDH model. By extension, since Braha and Reich show that the General Design Theory (GDT) by Yoshikawa (1981) is a special case of their framework, the GDT is also subsumed by the CDH model.

Regarding the other approaches in design research, Frayling (1993) proposed RtD (research through design), RfD (research for design), and RaD (research about design). According to his classification, design theories and design laws are provenient from RaD activities. Other high-level BDKs (such as design patterns, design guidelines, and design principles) are best understood as outcomes of RfD activities, since they help designers frame and solve design problems. At the middle level, design states are developed through RtD activities. Unlike Frayling's approach, however, we consider the design context knowledge to be an essential part of any reasonably complete formalism on design knowledge as well. We thus suggest augmenting Frayling's three-way classification with two additional activity types, RfDC (research for design context) and RaDC (research about design context). The former denotes the activities of detecting, elaborating, and triaging of contextual entities, and the latter concerns the activities of deriving and validating the needs, desires, and the design problem statement. This augmentation is echoed by Hevner and Chatterjee (2010), who suggest the decomposition of any design science research project into three spaces (the environment, design science research, and knowledge base) that are bridged by two associated research cycles: the relevance cycle and the rigor cycle. In comparison, the $\mathrm{CDH}$ model provides additional details on the internal structuring of the three layers, and facilitates the inferences of relationships among internal BDKs.

\subsection{Comparison with existing hierarchical models}

We note that the $\mathrm{CDH}$ model is not dissimilar to various hierarchical models of knowledge that have been proposed in the past in various non-design fields of inquiry, such as in sciences and philosophy. In those disciplines, knowledge has traditionally been organized into various bodies of diverse scope, such as scientific laws, formal models, theories, research paradigms (Kuhn, 2012), and research programs (Lakatos, 1980). Once acquired, bodies of knowledge are then ranked into neighboring strata (also called layers or levels), whereby knowledge found at one level gets transformed into knowledge at a higher level through various cognitive processes, such as decision making and reflection. For instance, the Data-Information-Knowledge-Wisdom (DIKW) model by Ackoff (1989) shown in Figure 2 stratifies knowledge-related constructs into:

- Data. This base level contains raw facts (i.e., numbers or symbols) obtained through observing and measuring a phenomenon.

- Information. This level contains answers to what, where, and when questions, and the answers are obtained by processing data in the lower level.

- Knowledge. This level contains answers to how and why questions, and the answers are obtained by processing information.

- Wisdom. Processed knowledge brings about enlightenment or understanding, which leads to the ability to exert correct value judgements about the observed phenomenon.

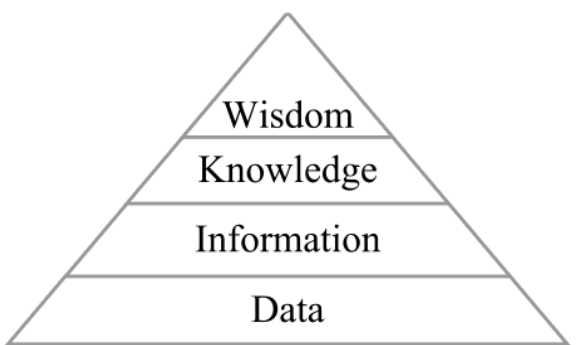

Figure 2. The DIKW hierarchical model of knowledge after Ackoff (1989)

If we compare the $\mathrm{CDH}$ model with Ackoff's model, we note similarities in the way raw data are sensed and facts about the design context are observed. However, while Ackoff's base level is uniform (containing just raw facts or data), the initial level in the $\mathrm{CDH}$ model is a composite consisting of 
observed (detected) unknowns and understood unknowns, which are then further triaged into relevant and irrelevant contextual design knowledge. As for the high-level design knowledge, the designer acquires, through many instances of design development, an equivalent of Ackoff's wisdom, which results in a good "grasp of the overall situation" (Barlas et al., 2005) and thus in the designer's ability to synthesize design patterns, design guidelines, and other kinds of high-level design knowledge.

While Ackoff's DIKW model is perhaps among the most renowned, other similar hierarchical models of knowledge have been proposed in non-design literature (see e.g., Newell (1982), Brachman (1979), Zimmerman (1980), Bloom et al. (1956), and Anderson et al. (2000)). For instance, the six cognitive activities of remembering, understanding, applying, analyzing, evaluating, and creating in the framework proposed by Anderson et al. (2000) can readily be applied to design. With regards to the factual, conceptual, procedural, and meta-cognitive knowledge proposed by the framework, the designer can use his or her procedural knowledge in order to build up the factual and conceptual bodies of knowledge. Meta-cognitive knowledge thus corresponds to a designer's competency with regards to exerting value, quality, and expert judgements in design.

With regard to design, Shedroff (1999) adopts the DIKW model and correctly identifies the importance of distilling information from data, and knowledge from information in design. However, it does not consider the separate BDKs found at each level of the CDH model. The related approach by Wodehouse and Ion (2010) similarly emphasizes the role of hierarchical models in design and adapts the DIKW model for the concept design domain.

\subsection{Benefits of the $\mathrm{CDH}$ model}

Fallman and Stolterman (2010) write about the current "disciplinary anxiety" in the field of IxD research. They acknowledge the "substantial latitude in terms of acknowledged research methods and approaches, ranging from quantitative empirical lab studies and qualitative observational studies to research-through-design and critical design experiments". This large number of possible approaches contributes to the overall uncertainty, field "anxiety", and fragmentation into partisan communities favoring a certain set of methods. The CDH hierarchy, on the other hand, affords a stable point that is invariant with regards to many methodologies used in the field of design research.

Moreover, design problems are hard and "messy"; in particular, they utilize knowledge from many sources that cannot be determined in advance (Guindon, 1990). We argue that the CDH model provides an intuitive, compact, reasonably complete, and extensible "cognitive map" (Tolman, 1948) of sources of design knowledge.

The $\mathrm{CDH}$ model may also be used to explain the genesis of previously reported design knowledge. For instance, if one considers the well-known set of design patterns by Alexander et al. (1977) through the lens of the $\mathrm{CDH}$ model, the authors first observed, analyzed, and comprehended a variety of different contexts in architectural and urban design, and then developed a number of architectural and urban designs corresponding to those contexts. We argue that this resulted in the authors' deep understanding of these designs, which enabled them to synthesize the aforementioned collection of design patterns. Without this understanding, obtained through extensive design development and repeated instances of comprehending design contexts in this particular sub-discipline of design, such a synthesis would have been challenging, if not impossible to achieve.

The CDH model also provides a straightforward roadmap for developing a desired, target body of design knowledge. Following the upward direction of knowledge generalization and evidence-based validation, a designer reaches an understanding of the design context (at the lowest CDH level). That understanding, in turn, will then inform the development of design states (middle CDH level). Based on the substantial accumulated design development knowledge, the designer or design researcher might also engage in the development of higher-level BDKs (top CDH level), such as design principles and design theories.

We reiterate, however, that higher-level design knowledge can be best developed, refined, and validated with the designer having successfully completed multiple design projects beforehand, namely when the designer or design researcher has accumulated substantial personal experience in developing design states, as well as in researching associated design contexts. This implies yet another temporal dimension to the static $\mathrm{CDH}$ model shown in Figure 1, and which we intend to address in future work. 


\section{Conclusions and future work}

In this paper, we presented the $\mathrm{CDH}$ hierarchical model of design knowledge, whereby such knowledge is classified into three levels: contextual design knowledge, design development knowledge, and high-level design knowledge. In addition, each level is characterized by associated sub-levels that refine the model further. We believe that this model can assist design practitioners and design researchers in better situating and understanding various BDKs created in both design practice and design-based research, as well as in informing future research related to the epistemological and methodological foundations of design and design-based research. Future work includes elaboration of the methods for generating and justifying BDKs, augmentation of the model by additional bodies of knowledge typically produced in design practice or design-based research, elaboration of ways to reuse design knowledge, illustration of temporal aspects related to building up BDKs, as well as refinement of the model in terms of how BDKs relate to each other.

\section{Acknowledgments}

The authors thank the reviewers for their useful comments. S. Kolaric thanks the Digital Building Laboratory, School of Architecture, College of Design at Georgia Institute of Technology for post-doctoral fellowship which made this collaboration possible.

\section{References}

Ackoff, R.L. (1989), "From data to wisdom: Presidential address to ISGSR", Journal of Applied Systems Analysis, Vol. 16 No. 1, pp. 3-9.

Anderson, L.W., Krathwohl, D.R. and Bloom, B.S. (2000), A Taxonomy for Learning, Teaching, and Assessing: A Revision of Bloom's Taxonomy of Educational Objectives, Pearson.

Alexander, C., Ishikawa, S. and Silverstein, M. (1977), A Pattern Language: Towns, Buildings, Construction, Oxford University Press.

Mahy, M. et al. (1987), A New Theory of Urban Design, Vol. 6, Center for Environmental Structures.

Barlas, I., Ginart, A. and Dorrity, J.L. (2005), "Self-evolution in knowledge bases", Proceedings of the IEEE Autotestcon 2005 Conference, Orlando, FL, USA, IEEE, pp. 325-331.

Bloom, B.S. et al. (1956), Handbook I: Cognitive Domain. Taxonomy of Educational Objectives: The Classification of Education Goals, Longman.

Brachman, R.J. (1979), "On the epistemological status of semantic networks", Associative Networks: Representation and Use of Knowledge by Computers, pp. 3-50. https://doi.org/10.1016/B978-0-12-2563805.50007-4

Braha, D. and Reich, Y. (2003), "Topological structures for modeling engineering design processes", Research in Engineering Design, Vol. 14 No. 4, pp. 185-199. https://doi.org/10.1007/s00163-003-0035-3

British Design Council (2007), Eleven lessons: Managing design in eleven global brands. [online] Design Council. Available at: https://www.designcouncil.org.uk/resources/report/11-lessons-managing-design-global-brands (accessed: February 14, 2020)

Carroll, J.M. (2003), HCI Models, Theories, and Frameworks: Toward a Multidisciplinary Science, Morgan Kaufmann.

Cross, N. (1984), Developments in Design Methodology, Wiley, Chichester.

Cross, N. (1999), "Design research: A disciplined conversation", Design Issues, Vol. 15 No. 2, pp. 5-10. https://doi.org/10.2307/1511837

Cross, N. (2001), "Designerly ways of knowing: Design discipline versus design science", Design Issues, Vol. 17 No. 3, pp. 49-55. https://doi.org/10.1162/074793601750357196

Daase, C. and Kessler, O. (2007), "Knowns and unknowns in the war on terror: Uncertainty and the political construction of danger", Security Dialogue, Vol. 38 No. 4, pp. 411-434. https://doi.org/10.1177/09670 10607084994

Dorst, K. (2011), “The core of 'design thinking' and its application”, Design Studies, Vol. 32 No. 6, pp. 521532. https://doi.org/10.1016/j.destud.2011.07.006

Fallman, D. and Stolterman, E. (2010), "Establishing criteria of rigour and relevance in interaction design research", Digital Creativity, Vol. 21 No. 4, pp. 265-272. https://doi.org/10.1080/14626268.2010.548869

Fitts, P.M. (1954), "The information capacity of the human motor system in controlling the amplitude of movement", Journal of Experimental Psychology, Vol. 47 No. 6, p. 381. https://doi.org/10.1037/h0055392

Frayling, C. (1993), "Research in art and design”, Royal College of Art Research Papers, Vol. 1 No. 1, pp. 1-5. 
Gardien, P. et al. (2014), "Changing your hammer: The implications of paradigmatic innovation for design practice", International Journal of Design, Vol. 8, p. 2.

Gero, J.S. (1990), "Design prototypes: a knowledge representation schema for design”, AI Magazine, Vol. 11 No. 4, p. 26.

Gero, J.S. and Kannengiesser, U. (2004), "The situated function-behaviour-structure framework", Design Studies, Vol. 25 No. 4, pp. 373-391. https://doi.org/10.1016/j.destud.2003.10.010

Gibson, J.J. (1976), "The theory of affordances and the design of the environment", Symposium on Perception in Architecture, Toronto, Canada.

Green, W. and Jordan, P.W. (1999), Human Factors in Product Design: Current Practice and Future Trends, CRC Press. https://doi.org/10.1201/9781498702096

Guindon, R. (1990), "Knowledge exploited by experts during software system design", International Journal of Man-Machine Studies, Vol. 33 No. 3, pp. 279-304. https://doi.org/10.1016/S0020-7373(05)80120-8

Hatchuel, A. and Weil, B. (2003), "A New Approach of Innovative Design: An Introduction to C-K theory", In Folkeson, A., Gralen, K., Norell, M. and Sellgren, U. (Eds.), DS 31: Proceedings of ICED'03, the 14th International Conference on Engineering Design, Design Society, Stockholm, Sweden.

Hatchuel, A. and Weil, B. (2009), "C-K design theory: An advanced formulation", Research in Engineering Design, Vol. 19 No. 4, pp. 181-192. https://doi.org/10.1007/s00163-008-0043-4

Hatchuel, A. et al. (2017), "Design theory: a foundation of a new paradigm for design science and engineering", Research in Engineering Design, Vol. 29 No. 1, pp. 5-21. https://doi.org/10.1007/s00163-017-0275-2

Hevner, A. and Chatterjee, S. (2010), "Design science research in information systems", Design Research in Information Systems, Vol. 22, pp. 9-22. Springer, Boston, MA. https://doi.org/10.1007/978-1-4419-5653-8_2

Höök, K. and Löwgren, J. (2012), "Strong concepts: Intermediate-level knowledge in interaction design research", ACM Transactions on Computer-Human Interaction, Vol. 19 No. 3, pp. 23:1-23:18. https://doi.org/10.1145/2362364.2362371

Kazakçi, A.O. and Tsoukias, A. (2005), "Extending the C-K design theory: A theoretical background for personal design assistants", Journal of Engineering Design, Vol. 16 No. 4, pp. 399-411. https://doi.org/ 10.1080/09544820500131300

Kolarić, S. (2016), Interacting with Design Alternatives, [PhD thesis], School of Interactive Arts and Technology, Simon Fraser University. https://summit.sfu.ca/item/16743

Kolarić, S., Erhan, H. and Woodbury, R. (2017), "CAMBRIA: Interacting with Multiple CAD Alternatives", In Çağdaş, G., Özka, M., Gül, L.F. and Gürer, E. (Eds.), Proceedings of the 17th CAAD (Computer-Aided Architectural Design) Futures Conference (CAADFutures'17), pp. 81-99. Springer, Singapore. https://doi.org/10.1007/978-981-10-5197-5_5

Kolarić, S., Woodbury, R. and Erhan, H. (2014), "CAMBRIA: a tool for managing multiple design alternatives", DIS Companion '14: Proceedings of the 2014 companion publication on Designing interactive systems, pp. 81-84. ACM. https://doi.org/10.1145/2598784.2602788

Kolko, J. (2010), “Abductive thinking and sensemaking: The drivers of design synthesis”, Design Issues, Vol. 26 No. 1, pp. 15-28. https://doi.org/10.1162/desi.2010.26.1.15

Kuhn, T.S. (2012), The Structure of Scientific Revolutions, University of Chicago Press. https://doi.org/ 10.7208/chicago/9780226458144.001.0001

Lakatos, I. (1980), Mathematics, Science and Epistemology: Volume 2, Philosophical Papers, Cambridge University Press.

Le Masson, P., Dorst, K. and Subrahamanian, E. (2013), "Special Issue on Design Theory: History, State of the Art and Advancement", Research in Engineering Design, Vol. 24 No. 2, pp. 212-243. https://doi.org/10. 1007/s00163-013-0154-4

Le Masson, P. and Weil, B. (2013), "Design theories as languages of the unknown: insights from the German roots of systematic design (1840-1960)", Research in Engineering Design, Vol. 24 No. 2, pp. 105-126. https://doi.org/10.1007/s00163-012-0140-2

Lynch, C. et al. (2009), "Concepts, structures, and goals: Redefining ill-definedness", International Journal of Artificial Intelligence in Education, Vol. 19 No. 3, pp. 253-266.

Marcus, C.C. et al. (1986), "Housing as if people mattered: Site design guidelines for medium-density family housing", Vol. 4, University of California Press, Berkeley, CA.

Mariage, C., Vanderdonckt, J. and Pribeanu, C. (2005), "State of the art of web usability guidelines", In: Proctor, R. W. and Vu, K.-Ph.L. (Eds.), The Handbook of Human Factors in Web Design, Lawrence Erlbaum Associates, Mahwah, NJ, pp. 688-700.

Newell, A. (1982), “The knowledge level”, Artificial Intelligence, Vol. 18 No. 1, pp. 87-127. https://doi.org/10. 1016/0004-3702(82)90012-1

Pahl, G. and Beitz, W. (2007), Engineering Design: A Systematic Approach (3rd Edition), Springer Science \& Business Media. https://doi.org/10.1007/978-1-84628-319-2 
Parent, A. (1992), "Analyzing design-oriented dialogues: A case study in conceptual data modelling", Design Studies, Vol. 18 No. 1, pp. 43-66. https://doi.org/10.1016/S0142-694X(96)00017-8

Rams, D. (2019), The Power of Good Design: Dieter Rams's Ideology, Engrained Within Vitsæ (Ten Principles for Good Design. [online] Vitsœ. Available at: https://www.vitsoe.com/us/about/good-design (accessed: February 14, 2020)

Razzaghi, M., Ramirez, M. and Zehner, R. (2009), “Cultural patterns in product design ideas: Comparisons between Australian and Iranian student concepts", Design Studies, Vol. 30 No. 4, pp. 438-461. https://doi.org/10.1016/j.destud.2008.11.006

Rzevski, G. (1981), "On the design of a design methodology”, In: Design: Science: Method, Westbury House, UK, pp. 6-17.

Schnerch, D. et al. (2007), "Proposed design guidelines for strengthening of steel bridges with FRP materials", Construction and Building Materials, Vol. 21 No. 5, pp. 1001-1010. https://doi.org/10.1016/j.conbuildmat. 2006.03.003

Sedlmair, M., Meyer, M. and Munzner, T. (2012), "Design study methodology: Reflections from the trenches and the stacks", IEEE Transactions on Visualization and Computer Graphics, Vol. 18 No. 12, pp. 24312440. https://doi.org/10.1109/TVCG.2012.213

Shedroff, N. (1999), "Information interaction design: A unified field theory of design", Information Design, pp. 267-292.

Shneiderman, B. and Plaisant, C. (2010), Designing the User Interface: Strategies for Effective HumanComputer Interaction (5th Edition), Prentice Hall.

Stolterman, E. and Wiberg, M. (2010), "Concept-driven interaction design research", Human-Computer Interaction, Vol. 25 No. 2, pp. 95-118. https://doi.org/10.1080/07370020903586696

Taura, T. and Nagai, Y. (2013), “A systematized theory of creative concept generation in design: first-order and high-order concept generation", Research in Engineering Design, Vol. 24 No. 2, pp. 185-199. https://doi.org/10.1007/s00163-013-0152-6

Tolman, E.C. (1948), “Cognitive maps in rats and men”, Psychological Review, Vol. 55 No. 4, p. 189. https://doi.org/10.1037/h0061626

Vlissides, J. et al. (1995), Design Patterns: Elements of Reusable Object-Oriented Software, Reading: AddisonWesley.

Weick, E.K. (1989), "Theory construction as disciplined imagination”, Academy of Management Review, Vol. 14 No. 4, pp. 516-531. https://doi.org/10.5465/amr.1989.4308376

Wodehouse, A.J. and Ion, W.J. (2010), "Information use in conceptual design: Existing taxonomies and new approaches", International Journal of Design, Vol. 4, pp. 3. https://doi.org/10.1080/15710880903393100

Woodbury, R. et al. (2013), "Exploring for Designs: Five Basic Elements", In: Armstrong, R. and Ferracina, S. (Eds), Unconventional Computing: Design Methods for Adaptive Architecture, Riverside Architectural Press and ABC Art Books Canada.

Yoshikawa, H. (1981), "General design theory and a CAD system”, In: Sata, T. and Warman, E. (Eds.), IFIP WG 5.2-5.3 Working Conference, North-Holland, Tokyo, pp. 35-58.

Zimmermann, H. (1980), "OSI reference model - The ISO model of architecture for open systems interconnection”, IEEE Transactions on Communications, Vol. 28 No. 4, pp. 425-432. https://doi.org/10. 1109/TCOM.1980.1094702

Zimmerman, J., Evenson, S. and Forlizzi, J. (2004), "Discovering and extracting knowledge in the design project", Proceedings of Future Ground'04 (Conference of the Design Research Society), Melbourne, Australia, The Design Research Society. 